\title{
Pedagogical Leadership in Action: Two Case Studies in English Schools
}

\author{
by
}

\author{
Trevor Male and loanna Palaiologou \\ (UCL Institute of Education)
}

[Published online in International Journal of Leadership in Education, 13 May, 2016]

DOI: $10.1080 / 13603124.2016 .1174310$

\begin{abstract}
This paper explores the construct of pedagogical leadership in action in two case study schools in England. Both schools investigated had headteachers who were recognised as excellent practitioners who had led their schools from a failing position to being judged as 'outstanding' and had successfully sustained and extended this status. Their behaviours thus corresponded to the ideals of pedagogical leadership which had been developed in previous research by the authors. This approach is an extension of ideas pertaining to learner-centred leadership where the key focus is on the personalisation of education for the benefit of the learner. Pedagogical leaders take this further, however, and ensure they are equally responsibile to the local community and the larger education system when determining appropriate action to support learning in their schools. The research reported here is based on interviews conducted with members of the school community (including students) to establish to how these pedagogical leaders determine effective action. The examination of data identifies six categories of leadership activity which contribute to the continued growth of these schools: establishing a success culture, managing external expectations, selection and induction of staff, managing a robust supportive environment, sustaining effective internal relationships and headteacher leadership behaviour.
\end{abstract}

\section{Correspondence:}

Dr. Trevor Male

London Centre for Leadership in Learning,

UCL Institute of Education,

20 Bedford Way, London. WC1H OAL

ENGLAND

E: t.male@ucl.ac.uk 


\title{
Pedagogical Leadership in Action: Two Case Studies in English Schools
}

by

\author{
Trevor Male and loanna Palaiologou \\ (UCL Institute of Education)
}

\section{Introduction}

Leadership in schools in England has drawn the attention of a number of researchers during the current century and has been dominated by numerous concepts, styles and models of what is perceived to be effective leadership (Moore et al 2002; Harris 2003(a), 2003(b), 2009; Day, 2005; Murphy, 2010; Bush 2011, 2012; Bush and Crawford, 2012; Smith, 2013; Hammersley-Fletcher, 2015; Elliot, 2015). In an earlier study Bensimon et al. (1989) suggested that the leadership literature and research is dominated by six leadership models: trait theory, behavioural theory, power and influence theory, contingency theory, cognitive theory and cultural/symbolic theory. Models or styles of leadership had tended to be based around the leader who behaves in a certain or "heroic" way (Kezar et al., 2006:2). Southworth, however, urged research to move away from such descriptive models of leadership and argued 'instead of striving for generalisations that homogenise leadership, we might be better advised to work towards more heterogeneity' (2002: 75).

In the context of education attempts to differentiate leadership have led to the examination of leadership development with "what happens to an organisation as it evolves over time" (Vierce 1995: 11), but this is still limited and problematic because:

... most commentators, certainly those writing during the past ten or twenty years, tend to conflate their own views about what leadership should be with their descriptions of what leadership actually is and fail to discipline either position by reference to empirical research. (Hopkins, 2001: 57)

Giles and Morrison (2010: 67) view leadership as "not firstly a concept, role, position or power, but a phenomenon" in an attempt to caution theorists who favour a modelling approach to leadership based on the premise that educational organisations are static and a specific leadership style "is applicable to every situation in time" (Kough and Tobin, 2001: 1). They argue that this phenomenon is 'uncertain' in nature because leadership is experienced 
differently according to context and situation and is constantly changing (Giles and Morrison, 2010). Blakesley (2011) suggests such confusion among educational leadership theorists to be as a result of constantly changing contexts, due to the "incompatibility of managerial approaches to leadership with educational desires and aspirations". He blames the way leadership within the educational context has been viewed through the lens of two major perspectives, based on management and social science, without having its own discourse. For this reason educationalists saw an essential need for academic dialogue which led to the coalescence of leadership with pedagogy (Sergiovanni 1984, 1990, 1992, 1998; Lefstein, 2005; Lipman, 2003; Hoy and DiPaola 2010). As a result a growing body of literature emerged that examined leadership in relation to pedagogy as:

- an inclusive concept of all aspects of teaching (Mortimore, 1999; Van Manen, 1991; Petrie, 2005; Yates, 2009);

- as a political tool that drives students' outcomes (Giles and Morrison, 2010); and

- as student centred learning and teaching (Kagan and Bowman, 1997; Hamilton and McWilliam, 2001; Heikka and Waniganayka, 2011).

The absence of an agreed explanation of pedagogical leadership has posed a challenge, however, for researchers who have encountered a lack of sufficient research based evidence on the concept (Cheeseman, 2007; Siraj-Blatchford, 2009; Andrews, 2009; Sumsion et al, 2009). The research that exists normally refers to responsibilities of the leaders that are not related with management and are limited to a dualistic relationships between teachers and learners and

"[...] lack of conceptual clarity and consensus about the foundational concepts of pedagogy and leadership" (Heikka and Waniganayka 2011: 501).

It appears that not only has pedagogical leadership not been sufficiently covered as compared to models of leadership such as instructional, learner-centred, distributed, and transformational leadership, but also that:

the term pedagogy is an ambiguous one when it is attached to the concept of leadership and requires further explanation beyond the seeming current determinism that pedagogical leadership is only about supporting teaching and learning. (Male and Palaiologou, 2015: 215).

Cecchin and Johansen (2009: 2) did investigate "professional pedagogical leadership" as an alternative theoretical approach, however, and described it as "connecting pedagogical developmental theory and leadership practice with classic leadership and management 
theory in one model [where] pedagogically educated leaders combine their pedagogical knowledge with their managing competences when performing leadership". Gotvassli (2006) similarly argued that "even if the term pedagogical leadership is not a precise term, it would seem that it is generally understood as leadership of learning processes".

In existing research there appears to be a tendency for the concept of pedagogical leadership to be understood more narrowly and to be used as a set of collective activities where facilitators of learning, not necessarily the ones who hold formal leadership roles, are responsible for students' learning experiences (Sergiovanni 1996,1998; Biesta and Miedema, 2002; Webster, 2009; Harris, 2009; Hoy and DiPaola, 2010; Emira, 2010; Heikka and Waniganayke 2011). Jappinen and Sarja (2011: 64-65) did extend the term by identifying "distributed pedagogical leadership" as:

... what characterizes a professional learning community when the educational actors intentionally share a common mission [...] Primarily, DPL refers to the distribution of interest, vision, aims and values for the purpose of achieving something more than the actors can perform separately. The issue is one of synergy creation where the whole is greater than the sum of its part.

Thus although there have been some attempts to theorise pedagogical leadership these have generally been limited to dualistic approaches between leaders and learners or teaching and learning (e.g. MacNeill, Cavanagh and Silcox, 2003). Previously we have argued, however:

On the one hand pedagogy needs to be understood beyond the simplistic position of the process of teaching and learning and on the other hand pedagogical leadership should strive not to follow models of effectiveness, but to seek links between educational outcomes and the set of social realities that these outcomes need to be measured. (Male and Palaiologou, 2015: 228).

We also consider that the discussion on pedagogical leadership has also been weakened by the dominance of the outcomes driven culture in schools which, in turn, has led to a vast body of research being conducted into different types of leadership, many of which are discussed more fully below. In this paper, however, we build upon previous work we have undertaken in order to explore the construct of pedagogical leadership as we interpret it. In this definition we see pedagogy as a key aspect of 
formal leadership where the responsibility for student learning is based on something more than the dualistic relationship between teachers and learners and an approach that includes influencing parental and local community involvement when seeking successful learning outcomes. Consequently we consider it is essential to investigate the nature of pedagogical leadership in contextual spaces such as schools and in contextual time within the outcomes driven culture for effective schools.

\section{Theoretical context of the study}

The construct of pedagogical leadership as we describe it in this context it is an extension of ideas pertaining to learner-centred leadership where the key focus of school leaders is on the personalisation of education for the benefit of the learner as opposed to the organisation or system. Consequently we consider pedagogical leadership differs from other approaches is that it is more than just supporting teaching and learning. We see it is responsive to the local community as well as to larger society, to be relevant to situation and context and to carry with it an expectation that actions should not be pre-determined (Male and Palaiologou, 2015). Pedagogical leadership thus builds on work relating to instructional leadership, where leadership behaviours focusing particularly on teaching led to larger than expected improvements in student attainment, which in turn led to the development of learning-centred and learner-centred leadership models. The essential difference between the latter two models was the way in which attention shifted from the needs of the system to the needs of the individual, although in our estimation both approaches still focused on what has been described as the 'academic press' (Hallinger, 2005: 3), which we define as the sustained drive for enhanced levels of student outcomes seemingly required by education systems across the world. As a consequence we developed an alternative approach to defining pedagogy, extending it beyond the relationship between teacher and learner in order to recognise the needs of the learner within the environment which we labelled internal and external pedagogical (social) axes:

- Internal axes (values, beliefs, culture, religion, customs \& local economy), and

- External axes (societal values, global economy, mass media, social networking, information communication technologies, national curriculum, the 'academic press' of student test scores).

Consequently we determined that pedagogical leadership sought to deal with these competing demands by exploring how: 
... the centrality of interactions and relationships among learners, teachers, family and community (i.e. their values, beliefs, culture, religion, customs and economic circumstances) interact with external elements (such as the global economy, climate and social phenomena that additionally influence the life of the community) in order to jointly construct knowledge. (Male and Palaiologou, 2015: 219)

From this perspective pedagogical leadership goes beyond the immediacy of the school buildings to recognise and deal with the tension between the needs and desires of larger society and those of the learner within their local community. In such a context we would expect leaders to take decisions and actions that were informed by both sets of pedagogical axes and to exhibit behaviours that support those ambitions, particularly in regard to sustaining internal axes.

We were anxious, however, not to modelise this leadership construct for, as we say above, leadership actions should not be pre-determined. We argue that research on educational leadership has been concerned with a journey of examining what makes leadership effective and it feels that there have been few attempts to problematise 'what is leadership about' and 'what is education'. In exploring those issues we determined that pedagogy is epistemic in nature in that it supports the creation rather than transmission of knowledge. Episteme is about striving to reveal general and everlasting truth (Mardht, 2007) and is scientific in nature rather than practically oriented (phronesis) or practically applied (techne). Leadership in education, however, is often seen as techne and presented as a monad, rather than a complex synthesis of the internal and external pedagogical axes. In other words such approaches to leadership provide a template for action that is not sensitive to the context rather than exploring new possibilities through "negotiating actions between learners, knowledge and their personal contexts, cultures and ecology of their community" (Male and Palaiologou, 2013: 228). A useful analogy here is the development of language which is not the responsibility of one person, but the combination of different views that make meaning which is understood by the community:

The word acquires its sense in the phrase. The phrase acquires its sense only in the context of the paragraph, the paragraph in the context of the book, and the book in the context of the author's collected works. Ultimately, the word's real sense is determined by everything in consciousness which is related to what the word expresses. (Vygotsky, 1934/1986: 347) 


\section{Research aims}

Thus we argue that leadership confined to the monadic focuses of education outcomes lacks the quality and depth required in complex and challenging situations, such as those experienced by the headteachers in the two case study schools we report on below. In this research paper we aimed to examine whether in our construct of pedagogical leadership successful leaders should seek to identify the dynamics of the ecology of the community. Such an approach, we suggest, will raise leadership to a level above generic "evidence based" practice which seek to underpin education outcomes (Cole, 2011) and recognise, instead, sequences of regular observable actions that have causality within a specific context. In this way we conclude at a theoretical level that leadership decisions and behaviour should not be pre-determined, but sympathetically reactive to both sets of pedagogical axes. Our previous investigation appears to have identified some headteachers who can exercise such an approach (Male and Palaiologou, 2015). Thus in the follow up case studies that we report here the aim was to clarify and verify that apparent success.

\section{Research Context}

As mentioned above in this paper we build we build upon previous work we have undertaken in order to explore the construct of pedagogical leadership in action in two case study schools in England, each of which had featured in our earlier research (Authors, 2015). The schools had each emerged from difficult and challenging positions they had occupied during the 1990s to become exemplars of transformation and to be recognised nationally as successful examples to which other schools should aspire. The primary school, for example, by the turn of the century was recognised nationally as being the was deemed to be the only one to meet all desired aspects of success identified by the the Office for Standards in Education, the national inspection service, (Ofsted, 2002) and subsequently being asked to make a presentation about their provision to Her Majesty's Chief Inspector of Schools. Meanwhile the secondary school had moved from abject failure in 1996 to be ranked 'outstanding' just a few years later (Ofsted, 2004) and to become a school recognised as one of only 12 judged to be 'succeeding against the odds' (Ofsted, 2009). Furthermore, in recognition of his work the secondary headteacher featured in this study was awarded several honours, including a knighthood in 2009. 
Their success in turning round their schools required substantial effort in the initial years with both employing carefully structured intervention strategies, which are described more fully below. A key feature of these two case schools, however, is that they demonstrated a capability to recognise achievement at an individual level that took them beyond using scores on test outcomes as the main determinant of success and continued to develop beyond the inspection benchmark that moved them from 'failing' to 'outstanding'. They have each developed an ethos of success that includes all organisational participants and celebrates all manner of outcomes. Their mission, therefore, was not merely to match governmental and societal expectations for academic attainment, but to also enhance the capability of their students (and indeed the staff) to be the best they can in terms of becoming a member of the wider society and be able to "steer their own pathway in later life" (Primary HT), a desire perhaps best summed up by a final year student at the secondary school:

The school instils a sense of sort of appreciation for the differences in society, but also shows you a way forward in order to be successful in wider society, not just academically, not just in traditional school ways. (Rob - Year 13 student)

Both headteachers had been in post for a substantial period by the time we conducted the research reported here, with the primary headteacher having a tenure of 21 years and her colleague in secondary school having been in post for 16 years, although he had served as a senior member of staff within the school for some seven years prior to that. The improvement process in each school had not plateaued, however, but had been extended. We adjudge both schools, therefore, to be matching one of the key tenets of 'high-performing organisations' in that they had consistently outperformed other similar bodies over a period of time (Collins, 2001).

We consider the behaviours of these headteachers and the systems they had created correspond to the ideals of pedagogical leadership we outline below and more fully in a previous paper (Authors, 2015). In this investigation, therefore, we sought to explore whether the claims made of their leadership as reported in our initial research in 2012 were substantiated by other members of their school community.

\section{The Research}


Our first investigation of potential pedagogical leaders in early 2012 had been initiated on the basis of published school outcomes and reputational information, but was only based on the views of the formal leader in each of the settings we examined. With their permission, therefore, we determined in this study to investigate the views of other members of the two case study school communities to see whether there was evidence that the claims the headteachers had made were substantiated in practice. As researchers we were experienced and familiar with the phenomenon of school reputation being sustained by effective marketing and careful information management, so we sought to see if the surface level claims of the headteachers ran deep and were embedded within other members of the school communities they represented.

In the search for pedagogical leadership in action we undertook in-depth interviews at the secondary school in November 2012 and in the primary school in January 2013. Each participant to be interviewed individually was sent an outline of the areas we wished to investigate for them to consider in advance of them meeting with us. The key issues were:

- Ways in which they and other members of the school community were able to participate in decision-making;

- The structures, internal processes and relationships within the school that supported the leadership and management of student learning;

- Examples of productive and synergistic relationships where learners, teachers, parents, community and government have worked together to support learning in a manner natural to the learner's locality;

- Their views on the way in which the school addressed the seeming relentless drive for higher scores on national tests;

- Whether they experienced a supportive environment for their practice and development;

- Examples of practice where there was emphasis on learners working together to achieve aims each could not achieve on their own.

Five individual interviews were conducted at the secondary school with three members of the senior leadership group, one other member of senior teaching staff and a governor (also a parent), together with a focus group meeting focusing on the same issues with seven students of the School Council. In the primary school four interviews were conducted with the deputy headteacher, a teacher, a teaching assistant (who was also a parent) and a governor. We also interviewed both headteachers again after we had completed all the interviews with other participants, giving us a total of 11 individual interviews and one student focus group meeting. 
Each interview lasted between 30 minutes and an hour and was undertaken in camera away from the participants' normal workspace, albeit in the same building. Ethical clearance was sought and granted from the researchers' employing university and participants were asked to sign a letter of informed consent which assured their anonymity and provided the right to withdraw at any stage.

Interviews were audio recorded and subsequently transcribed by a professional service. The transcripts were then edited to correct errors and remove repetitive statements and social discourse before being returned to participants to confirm they were a true record of the meeting and fairly represented their views. Opportunity was offered to amend or delete content accordingly with all such requests honoured by us as the researchers. The consequence was that we had access to an agreed transcript, thus making the data secure. All other typical ethical procedures were undertaken in line with code of practice required by our employers which, in turn, is aligned to national and international standards. The transcripts were analysed using open coding to determine emergent themes (Cogill, 2008). The resulting codes were refined by repeated analysis and then used to define recurring themes and patterns, resulting in the creation of core categories (Glaser and Strauss, 1967). This inductive process enabled emergent elements of the data to be analysed. The emergent categories were examined by an independent colleague to obtain measures of inter-rater reliability. Agreement ranged between 85 and 96 per cent. Disagreements were resolved by discussion.

The following three main categories were emerged and will be discussed into details below:

1. The content

2. Intervention strategies

3. Sustaining and Extending the Improvement Process (with six sub categories)

\section{The context}

As suggested above the schools were in difficulties when these headteachers took up post, with both also being in challenging circumstances. The primary school was in a semi-rural village in the North East of England which drew pupils from around the locality, including from a nearby large town with significant social challenges. The most common parental occupations were low income in agricultural or petro-chemical distribution, but there were 
also pockets of chronic unemployment. The secondary school was in an outer London borough with a mainly (almost exclusively) white working class population at the time the headteacher took up post. At the time of taking up her post as headteacher the primary school had previously failed an inspection conducted by Her Majesty's Inspectorate ( $\mathrm{HMI}-$ this was prior to the establishment of Ofsted in 1992). Meanwhile the secondary school was notorious at the time for endemic student misbehaviour described by the Deputy (who was a pupil of the school at the time) as having a reputation of this school "that was rock bottom, I mean, it was terrible, and the school went through its really bad phase in the three years before he was appointed as headteacher". Interestingly the student population of the schools have changed over the course of their tenure, but this is not considered a causal factor for improvement. Unlike some schools that have actively sought to change the student population by attracting more children of middle class parents these schools intentionally sought to work with the local population and to enhance their life chances. Indeed the catchment area of the secondary school (which has over 2000 students) is just 1.3 square miles. We will return to the changing nature of the school population later after we have examined some of the successful outcomes of these schools.

Children now leave the case study primary school as literate, numerate and with a keen understanding of the part they can play in shaping their own lives and becoming successful. They score well on national tests, but more importantly enjoy an environment where it is not only challenging to learn, but it is exciting, fun and they are happy - a working environment that is described as being "like a family" (primary teacher). In the secondary school they have moved from a situation of aggressive student indiscipline and low academic achievement (even none in some cases) to a caring environment with high levels of academic achievement. Student attainment has risen from a point in 1997 where 21 per cent of the school population left with no qualification to the current situation where every student gets a qualification, over 80 percent get five good grade GCSEs at Key Stage 4 (including Mathematics and English) and 87 students in the sixth form were offered places at university in year 2013-14. More importantly the students feel part of a "learning community" (Ellie Year 12 student) with "mutual respect not only between the teachers and the pupils, but between the pupils as well" (Audrey - Year 13 student). The overall impact of the school is perhaps best summed up by the same student who after a very difficult start in the school 
now leads the debating society and is about to join a top ranking university when she says "they massively changed the way I feel about school today".

Our investigation thus sought to establish how these schools effected the change and, latterly, sustained and extended their levels of performance.

\section{Intervention Strategies}

Different approaches were adopted in the schools in the first instance, primarily because discipline was such a major issue confronting the headteacher of the secondary school. As a member of teaching staff for some seven years he was familiar with the area and the students and carried with him a strong reputation for achieving success in the most challenging of circumstances. Other members of staff within the school, many of whom are still there today, also enjoyed similar levels of success, but outside the classroom the atmosphere was toxic with public spaces often being no-go areas except for the most challenging students. The school's local reputation had plummeted and parental interest was minimal and, on occasion, aggressively intrusive. His first actions as headteacher - aligned with what is now recognised as the standard approach to a failing secondary school - was a strong emphasis on restoring discipline, on teachers being required to prepare and deliver good lessons and on high levels of support for students with learning challenges. He took up his appointment in the month of May and was thus able to plan for a fresh start in the new academic year in September, with one of his first tasks being to introduce school uniform. It was here he demonstrated his understanding of the local context by recruiting some of the most notorious students to act as walking models for the new uniform during the second half of the summer term. The effect on other students was as may have been expected in that they were keen to wear the new uniform as well when it became available at the start of the new school year.

His second step was more dramatic and incredibly demanding of him and his senior team in that he excluded troublesome pupils on an epic scale, with numbers into the hundreds. His rationale was simple - it allowed him to talk to the parents as students would not be allowed back into school until that meeting had been held and conditions agreed. This was an incredible task that extended his and the senior management team's working hours exponentially, but it worked. When the dust settled only 12 students were permanently 
excluded and since that time only two more have befallen that fate. This initial intervention was backed up by a zero tolerance approach to behaviour and uniform and is perhaps best illustrated by the way in which he and his team worked with local shopkeepers, service providers and other members of the community to promote an improved image of the school. It was not uncommon for him to appear on a local bus, for example, and to the bemusement of London Transport staff to ask for details of any inappropriate behaviour from students at his school. The message got out quickly to the local community, however, and the school began to be perceived as a secure environment that was unlikely to return to the former levels of indiscipline and notoriety. This base gave him the platform to focus on his real concerns in his words: "providing an opportunity for all students to flourish, to achieve and to become effective citizens in the future society".

These were also the motives that drove the primary headteacher who set about an approach to changing the school that was equally revolutionary in comparison to the secondary school, albeit without the drama of adolescent confrontation. Her mission, as described above, was to provide a learning environment for the children that was not only safe and secure, but one that provided a challenge, was fun and sustained the thirst for knowledge that is inherent in all young children. She was determined that children who left the school did so with an enthusiasm for learning and the skills to make their way successfully through life. Her first choice was to dispense with a standard curriculum and timetable. Instead the curriculum was to be topic based and featured careful planning and mapping by teachers to ensure that all learning objectives within the National Curriculum were still being met, but within an environment where children's enthusiasm for learning was sustained. The time to be spent each day on an issue, a topic or a task were to be determined by the class teacher, rather than a fixed timetable, meaning that each class took breaks as and when appropriate. It needs to recognised that this was done at a time when the National Curriculum, introduced through the 1988 Education Reform Act, provided a very prescriptive approach to primary school organisation (a national policy approach that got even more restrictive as years went by). Her opportunity to enact this model of non-prescriptive curriculum and timetable was provided because she took over a failing school precisely at the time when HMI inspections were giving way to the new Ofsted era, thus giving the school the space to change radically before anyone could tell them otherwise. By the time these external agencies focused their attention on the school again major improvement was already evident. 
Here we see one of the principal elements of pedagogical leadership in action, the determination to provide an effective learning environment for all students and not just those who contribute to improving the scores on national tests for the benefit of the school's reputation. The primary school, for example, is well known for its highly effective inclusion practices. In order to do that at the secondary school, however, discipline was required first in order to provide the opportunity to focus on providing good learning opportunities. The introduction of the 'Good Lesson', still a feature in the school today, was not only essential for restoring order to the school, but was seen by the headteacher as a student right. This is evidence of the trust and respect, later to become mutual, the he and his teachers placed in the students. His declaration that "if these children have been let down that's a disgrace, it's outrageous" sums up his philosophy underpinning the route to improvement. In both schools, therefore, it is not just about meeting the aspirations of government, external agencies or society at large, it is about doing the right things to provide opportunities for students to make the best of themselves. The headteachers of these case study schools were thus responding more to the internal rather than external axes of their environment we describe above. Here we can see the parallels with the so-called 'Maverick' headteachers, unearthed by the government sponsored investigation into school leadership, who went about their school improvement process in a way that was not recommended, but was nevertheless effective (Hay Group, 2002).

\section{Sustaining and Extending the Improvement Process}

Creating the necessary change is not that difficult or complicated, however, it is sustaining and extending the level of improvement that is the hard task. In many ways, it could be argued, the intervention strategies of both headteachers were not novel if they are judged solely on their intention to stabilise the school, ensure a safe working environment and to provide planned learning opportunities that at least matched basic expectations of government inspection agencies. There are myriad examples of headteachers who have effected the 'turn-round' of a failing or struggling school though using similar intervention strategies as our case study headteachers, but very few examples where they have continued to build on that initial intervention to sustain and extend the improvement process. The binding factors in these two case study schools are the basic value sets of both headteachers, 
coupled with their willingness to confront challenges with innovative approaches (and unquenchable desire). The examination of our data suggests there are six sub categories of activity which contribute to the continued growth which we will use for analysis of these case study schools:

1. Establishing a success culture

2. Managing external expectations and demands

3. Selection and induction of staff

4. Establishing and maintaining a robust supportive environment

5. Effective internal relationships

6. Headteacher leadership behaviour.

\section{Establishing a success culture}

The starting point for the secondary headteacher was "forget where we are, we're going to do well" thus, according to the Assistant Headteacher "creating expectations that the staff place on the pupils not being affected by the area in which our school's based", a situation best summed up as:

It is all about achieving and just giving them a different view of themselves. Coming from a deprived borough [area] we don't use that as an excuse and we wouldn't let anybody hide behind that. (Parent Governor)

From Day One he sought to celebrate success both publicly and privately, with school assemblies being used as a primary vehicle, an approach described by the Deputy Headteacher as "superb and they're at the heart of us delivering our ethos" before going on to illustrate how the school will celebrate individual success equally for any aspect of the individual student's life irrespective of where that took place - "it means doing your best consistently". Many times, however, success was noted in private conversations in corridors or public places with a quiet word of congratulation being as effective as a public display. Students at the school welcomed this wholeheartedly as demonstrated by a Year 12 School Council member who said "even if you're not the best at the academic side of the school, you will get a chance to shine and they will recognise what you've done" (Gabbie).

Similarly the primary school was looking to recognise special skills or talents as summed up by the headteacher and confirmed by staff at the school:

I believe that we can't all be academics, we can't expect the children all to be academic, but what I'm pretty certain of is that every child has something special to 
offer and it our duty to find out what that is. If all we are going to do is teach literacy and numeracy, with the rest of it all squashed into a small amount of time, we are letting those children down. We are never going to find out what that special skill or talent is that they have. So we have always maintained a really broad and balanced, but very relevant curriculum [where they are] engaged in practical, first-hand experiential, investigative activities.

\section{Managing External Expectations and Demands}

There are three main sets of stakeholders in any state maintained school: the staff and students of the school, the local community and government as the funding agency. For any school to sustain a plan of action at least two of these three sets of stakeholders must be aligned in their intent. This does not mean the third set should be ignored, but what we saw in these two case study schools was a determination to focus on the needs of the school and the local community rather than government demands and expectations. Such demands and expectations were filtered and managed to the benefit of the school in line with the work of Selznick (1983) who distinguishes effective leaders from everyday managers by stating that leaders act on the boundary tensions between the core activities of an organization and the wider demands, challenges and opportunities of its environment. This work of boundary spanning involves protecting and supporting critical organizational functions while simultaneously attempting to accommodate external demands. The secondary headteacher recognises this in his statement that "the best interests of the school was to continue to be tied in with the community, with the Council and with the Local Authority", a view echoed by a Year 13 student from the School Council who pointed out that "we were voted like one of the worst places to live in the UK, it doesn't take away from how well this school does in trying to address those social issues" (Azaan). The school results on GCSEs and ' $A$ ' levels are testimony, however, to a commitment to satisfy government, a situation akin to that described by the primary headteacher:

We are not data driven at our school, we are measured by data so we don't cut our noses off to spite our faces, we know that's what we're measured on and we don't keep getting an outstanding Ofsted judgement without high standards as well as an innovative curriculum. [...] We don't teach to any tests, however. We've never done the Literacy Hour and we've not done the Numeracy strategy. We continue to teach how we believe children learn best and the way that children find most interesting and motivating. I want children to be happy and thrive in school, but I also want them to leave our school still with a thirst for learning and a thirst for knowledge and l've seen too many children switched off in primary schools and leaving the school absolutely brain dead [...] they've just been taught to jump through hoops, there is no real understanding of learning. 


\section{Selection and Induction of Staff}

A truism of management is that 'you are where you are, and often not where you want to be'. In each of our case study schools they inherited staff with a variety of talents and motivation and yet quickly established an ethos of success built on commitment. Their own dynamism undoubtedly contributed to that in the initial stages, but what they want (as all good leaders do) was to make sure that future appointments matched and extended the culture they had established. The first stage of that process lies with selection. The primary headteacher was quite open about their approach, saying "we choose very carefully", in order to make sure the candidate would subscribe to the culture and ethos of the school. The selection panel of the school used this as a key aspect of the person specification for the job, but were not totally slavish towards that criterion:

l've sat at interviews when we haven't rejected them because we didn't think they'd fit, but if they didn't fit it was one of the things against them. We have got to keep this good, progressive atmosphere and they've got to fit in. (Governor)

Clearly careful selection was vital to a small primary school as one member of staff can make a major difference to the atmosphere and performance. Similar attention to detail was given to selection of new staff in the much bigger enterprise that was the secondary school, but equally huge efforts were made in terms of induction with all newly appointed staff required to attend an off-site residential weekend workshop in the company of established staff:

In the first term we take away every new member of staff on a residential, we've been doing this for 16 years. We have an intensive two day course at the end of September on all aspects of teaching, leadership and management, the journey the school's been on and l'll present the story. What happens is we invite 50 established members of staff, subject leaders, second in charge, to be with the new recruits. That has worked brilliantly because it's a refresher course for everybody that's still part of the institution, but if you listen to the feedback that we have from all the new recruits, they think it's absolutely fantastic. (Secondary Headteacher).

Here we are witnessing a rare example of an organisation investing heavily in inducting new recruits to the established working practices of a successful organisation. It is common for secondary schools in London (and other major cities) to experience relatively high turnover of teaching staff as many young people use the experience of working in the capital as part of their transition into full adulthood. Interestingly, however, the secondary school shows a terrific retention capability with larger than expected numbers of staff staying much longer 
than they anticipated, in some instances making it a lifelong career. This may well be a feature of the quality of internal relationships and, in the case of the secondary school, opportunities for promotion within the institution. Similar desire for retention was also witnessed in the primary school with the Deputy Headteacher, for example, having stayed for 17 years despite a previous almost nomadic existence. There are counter effects to this, of course, in that some good and otherwise committed members of teaching staff recognise they will have to move on in order to gain promotion as highlighted by the class teacher who said: "If I could progress here, even though there is a quite a big commuting cost to get here, I would definitely stay for longer". The outstanding quality of working within the school was a common feature, but was not a status achieved by accident as will be seen in the next section.

\section{Establishing and maintaining a robust supportive environment}

This and the next section on internal relationships are considered key elements of moving the schools beyond the status of outstanding and include processes akin to those described of organisations that have gone from 'good' to 'great' (Collins, 2001). It is the headteacher of the secondary school who described internal atmosphere as "a very robust supportive culture" in order to focus attention on making demands of participants that led to a constant search for enhanced performance, an ethos eloquently described by the Assistant Headteacher:

There are high standards and I would call it 'supportive accountability'. Everybody knows as a teacher what's expected of them, they know they're expected to deliver for the pupils and so everybody is accountable for their result. The ethos is incredibly supportive and incredibly high standards are expected of the pupils and of the teaching staff.

A similar climate existed in the primary school and described by the Deputy Headteacher as "an ethos that they grow into [...] it seeps through the whole building and I think the children sense it. [...] everybody's just so supportive of everybody else". The result is that all participants we interviewed highlighted the importance of that support, from the 82 year old governor of the primary school (also a volunteer teaching assistant) who said "I'd do anything for this place, it's so good to me" though teaching staff like the Head of Year 11 in the secondary school who declared "when I came here the leadership and the support was evident and I felt that that's what I needed to be able to have a good foundation and flourish from there - they have given me opportunities and confidence" and to the students like Rob (Year 13) who indicated that "at every opportunity they've motivated me to go forward". The 
ethos of robust support in turn adds to motivation of all participants to do more than the bare minimum as summed up by the parent governor of the secondary school:

That goodwill stems from the headteacher and with the kind of ethos that he's created people are happy to go the extra mile.

\section{Effective internal relationships}

Not only were the headteachers people-centred, but there was an obvious mutual high regard between staff, between staff and students and with all school members and the local community. The evidence of good relationships was extremely strong. Students in the secondary school talked about teachers being "firm but fair" (Azaan, Year 13 student), "there's not a teacher that you can't speak to" (Rob, Year 13 student) and supportive "if you need help you know you can go to any teacher and they will help you" (Ellie, Year 12 student). Teachers referred to the open and supportive nature of the environment: "how friendly people were and they were there to help you" (Class Teacher - primary school) and "you feel immediately like there is a common agenda and my judgement is valued" (Head of Year 11 - secondary school) and that "nobody is afraid to ask for help" (Assistant HT - secondary school). This climate in the schools was summed up by the governor of the primary school when she said "they treat everybody right". The sense of openness and belonging was evident in both schools and is best described by staff in the primary school:

It's just such a warm feeling. It's lovely. (Teaching Assistant)

We're so open with each other and the respect that people have for each other, even though we're all very different, we all want the school to do well and the children to do well. That is just the success, I think, of the school. (Deputy Headteacher)

The starting point for this was the headteachers, of course, who exemplified the behaviours they expected of others. Both were described as good listeners with the secondary headteacher described by his deputy as "always receptive to other people's opinions" and the primary headteacher being able to resist talking until she had finished listening according to the Teaching Assistant who reported her as saying "I want you all to speak before I speak". The real key to establishing and maintaining this atmosphere lies, however, with each headteacher seeking high levels of inter-personal communication.

I try to be a very hands-on person and I will talk to staff on a daily basis, and they know, they see me in the classrooms and they see how I still love doing that. I hope 
that I can pass my enthusiasm and still show them that that is my interest. (Primary Headteacher)

In a world that's impersonal, in a world that's driven by emails and texts and so on, I'm actually physically talking to them about values - and that's attractive. (Secondary Headteacher)

\section{Headteacher leadership behaviour}

We can see, therefore, that both headteachers in our two case study schools have moved from the directive, deterministic, even authoritarian mode they exhibited in the early days of their tenure to a more open, democratic approach that seeks alternative views rather than compliance or even consensus. Individuals are "trusted to carry out their responsibilities without too much interference" according to the deputy headteacher of the secondary school, yet can seek guidance and support when they need it "you always feel that her door is always open as a parent and as a member of staff" (Teaching Assistant/Parent - primary school) and "if anything happened she would always be there to help you out" (Class Teacher primary school). Both strove to be in constant contact with all members of the school as evidenced by the primary headteacher (see above) and by the statement from the secondary headteacher "visibility, presence is absolutely essential".

What remained essential to continued success, however, was the ability of both headteachers to be prepared to take action in favour of the need of their learning community, particularly the student body if circumstances demanded. "At the top of this organisation is a headteacher that has got a very clear view about right and wrong" declared the Deputy Headteacher of the secondary school and a recognition of her power by the primary headteacher who was happy to tell the staff "don't forget at the end of the day whatever you do lies with me, it's my neck on the block". Both, therefore, were happy to assume personal responsibility for decision making when they felt it necessary, but preferred to act in a collegial way, based on their value set. The final word on their leadership behaviour falls to the secondary headteacher:

Start with your values. Human beings like to identify, they're tribal, they like to identify with their school and they like to identify with the people. Staff who have those values can take tough decisions, can keep the ship on a steady course and can have a meaningful dialogue about teaching. I think that's where you get excellence.

\section{Conclusions}


As our data reveal the approach to leadership exhibited by headteachers in the two case study schools is to seek for practices that are sensitive to context and apportion responsibility for subsequent necessary actions to those people who are at the forefront of delivering organisational goals. In other words the two headteachers we saw in action here had the capability to identify what was important and relevant to the needs of their school community and to build the capability for others to enact those aims.

This is an approach which again mirrors the work undertaken to identify the skills exhibited by the formal leaders of high performing organisations who "build enduring greatness through a paradoxical combination of personal humility plus professional will"'(Collins, 2001:20). The research by Collins and his team that underpins these findings is substantial and included the review of books, articles, case studies, financial analyses and annual reports for 1,435 established companies. The research totalled 980 combined years of data, included 84 interviews with senior managers and board members together with the scrutiny of the personal and professional records of 56 CEO in the search to find every extraordinary case that made a leap from no-better-than-average results to great results. In fact, the 11 goodto-great companies that they found averaged returns 6.9 times greater than the market average. The leaders of such companies it was concluded:

Channel their ego needs away from themselves and into the larger goal of building a great company. It's not that [such] leaders have no ego or self-interest. Indeed they are incredibly ambitious - but their ambition is first and foremost for the institution, not themselves [original emphasis]. (Collins, 2001: 21)

These leaders were willing to listen more than they spoke and always considered that they did not have the monopoly on good ideas. In addition they placed trust in the people who must deliver on the agreed values and ambitions of the organisation, thus subscribing to the concept of 'subsidiarity' (Handy, 1995). This is the organising principle that matters ought to be handled by the smallest, lowest or least centralised competent authority. The power to act thus belongs to the point in the organisation where the most impact can be achieved.

To use examples of leadership behaviour taken from Collins' work may seem to contradict what we said earlier as the success of organisations he and his team studied was measured simply by improved outcomes, their profit margin. Conversely we had suggested that pedagogical leadership was driven by motives other than learning outcomes as measured by 
attainment on standard tests. We do not see this conflict as problematic, however, as we were more interested in the parallels between headteachers in our case study schools and the behaviour of the Chief Executives studied by Collins, each of whom focused on improving organisational processes and not just maximising the profit margin as a way of achieving desired outcomes. In both case study schools the headteachers were "modest and wilful, humble and fearless" (Collins, 2001: 22), but equally importantly placed trust and responsibility in the hands of those people who could make the most impact on the life chances of children within their school. Their key role was to sustain the driving force, the 'fierce resolve' Collins refers to, that had taken their school away from failure to increasing success on a variety of criteria that were important to the internal and external pedagogical axes.

Thus there had been recognition by these two headteachers that the monadic idea of education outcomes as the driving force for a school is doomed and had to be supplanted by what we have described as leadership praxis, an approach which seeks actions that are justified by the dynamics of the ecology of the community (Male and Palaiologou, 2015). A monadic focus on education outcomes would lack the quality of pedagogical leadership that has been evidenced in our data, the key characteristic of which is the responsible exercise of judgment in support of student learning needs. In our estimation this was the most important feature of the six categories of extending and sustaining the improvement process, it was the driving value that underpinned their behaviour. Whilst all six categories combined were important, it was only the last three - establishing and maintaining a robust supportive environment, maintaining effective internal relationships and headteacher leadership behaviour - that set these two leaders apart from other contemporaries. These attributes we deem as critical if any headteacher is to move beyond competent leadership to become consistently outstanding. The abilities to be demanding, whilst not dominating, coupled with the behaviours associated with the 'fierce resolve' and 'humility' identified by Collins (2001) created the environment of sustained improvement.

To support the construct of pedagogical leadership we consider evident in these two headteachers we draw on the quote from the ancient Greek play writer Sophocles in Antigone: Hermeon argues against his father decisions, saying "Father, only gods endow a man with reason, the finest of all gifts, a treasure". This quote echoes the voices of the 
headteachers in our case studies in that whilst they felt the pressures from external axes such as Ofsted and policy makers they worked assiduously to sustain the internal axes of their school community. It often feels as if formal leaders in educational contexts these days should obey "authority" right or wrong and avoid autonomous actions of pedagogical leadership as external axes do tend to force a discipline and fragment actions in order to ensure education outcomes, thus making leadership a techne. Pedagogical leadership instead seeks to enhance reasoning and create an episteme echoing Foucault's definition:

I would define the episteme retrospectively as the strategic apparatus which permits of separating out from among all the statements which are possible those that will be acceptable within, I won't say a scientific theory, but a field of scientificity, and which it is possible to say are true or false. The episteme is the 'apparatus' which makes possible the separation, not of the true from the false, but of what may from what may not be characterised as scientific [...]. However, if in any given culture and at any given moment, there is always only one episteme that defines the conditions of possibility of all knowledge, whether expressed in a theory or silently invested in a practice. (Foucault, 1970:168)

Our final thought here is that whilst we do not discard the importance of education outcomes, as judged by tests on national scores, our data have revealed is that they should not be the sole causal feature of actions in the normal educational context. Pedagogical leadership thus runs the risk of displeasing external authority whilst at the same time criticising the rules, ways and practices by which their schools are run. The core focus remains, however, that the experience of success for individual students is equally, or even more, important than the success for the educational system. As can be seen from our two case study schools here, both are possible providing formal leadership responsibility is primarily pedagogical in nature.

\section{References}

Andrews, M. (2009). 'Managing change and pedagogical leadership'. In: A. Robins and S. Callan (Eds.) Managing early years settings. Supporting and leading teams. London: SAGE, 45-64.

Bensimon, E., Neumann, A. and Birnbaum, R. (1989). Making sense of administrative leadership: The "L" word in higher education. ASHE-ERIC Higher Education Report, 1.

Biesta,G. and Miedema, S.(2002). Instruction or pedagogy? The need for a transformative conception of education. Teaching and Teacher Education, 18, 173-181.

Blakesley , S. (2011). Defining educational leadership in Canada's Yukon territory: "Hmmm, that's a good question...". Canadian Journal of Education, 34 (1), 4-36. 
Bush, T. (2011). Theories of educational leadership and management (4/e). London: Sage.

Bush, T. (2012). Leadership in early childhood education. Educational Management Administration and Leadership, 41(1), 3-4.

Bush, T. and Crawford, M. (2012). Editorial: Mapping the field over 40 years: a historical review. Educational Management Administration and Leadership, 40 (5), 537-544.

Cecchin D. and Johansen M. W (2009). Integrating leadership and pedagogy in early childhood institutions professional pedagogical leadership. Paper presented in the European Early Childhood Education Research Association conference, Strasburg, August.

Cheeseman, S. (2007). Pedagogical silences in Australian early childhood social policy. Contemporary Issues in Early Childhood, 8(3): 244-254.

Cogill, J. (2008). Primary teachers' interactive whiteboard practice across one year: Changes in pedagogy. Available at: http://juliecogill.com/Chapter_2.pdf - accessed 22 March, 2016.

Cole, D. (2011). Educational life-forms: Deleuzian teaching and learning practice. The Netherlands: SensePublishers.

Collins, J. (2001). Good to Great. London: Random House.

Day, C. (2005). Principals who sustain success: Making a difference in schools in challenging circumstances. International Journal of Leadership in Education, 8(4), 273-290.

Day, C. and Leithwood, K. (2007). Successful principal leadership in times of change: An international perspective. Dordrecht, The Netherlands: Springer.

Elliot, G. (2015). Critical practice leadership in post-compulsory education. Educational Management Administration and Leadership, 43(2), 308-322.

Emira, M. (2010). Leading to decide or deciding to lead? Understanding the relationship between teacher leadership and decision making. Educational Management Administration and Leadership, 38(5), 591-612.

Foucault, M. (1970). The order of things: Archaeology of the human sciences. London: Tavistock/Routledge.

Gage, N. (1978). The scientific basis of the art of teaching. New York: Teachers College Press.

Giles , D. and Morrison, M. (2010). Exploring leadership as a phenomenon in an educational leadership paper: An innovative pedagogical approach opens the unexpected. International Journal of Teaching and Learning in Higher Education, 22 (1), 64-70.

Glaser, B., \& Strauss, A. (1967). The discovery of grounded theory. New York: Aldine.

Gotvassli, K. (2006). Kindergartens: Organization and management. Trøndelag: Universitetsforl. 
Hallinger, P. (2005). Instructional leadership and the school principal: A passing fancy that refuses to fade away. Leadership and Policy in Schools, 4, 1-20.

Hamilton, D. and McWilliam, E. (2001). 'Ex-centric voices that frame research on teaching', In V. Richardson (Ed.), Handbook of research on teaching (9/E). Washington DC: American Educational Research Association, 17-43.

Hammersley-Fletcher, L. (2015). Value(s)-driven decision-making: The ethics work of English headteachers within discourses of constraint. Educational Management, Administration and Leadership 43(2), 198-213.

Handy, C. (1995). The empty raincoat. New York: Random House.

Harris, A. (2003a). 'The changing context of leadership: Research, theory and practice'. In A. Harris, C. Day, D. Hopkins, M. Hadfield, A. Hargreaves and C. Chapman. Effective leadership for school improvement. London: RoutledgeFalmer, 9-25.

Harris, A. (2003b). 'Teacher leadership and school improvement'. In A. Harris, C. Day, D. Hopkins, M. Hadfield, A. Hargreaves and C. Chapman. Effective leadership for school improvement. London: RoutledgeFalmer, 72-83.

Harris, A. (2009). Distributed school leadership. Evidence, issues and future directions. Sydney: Australian Council of Educational Leaders.

Hay Group (2002). Maverick: Breakthrough leadership that transforms schools. London: Hay Group Management Ltd.

Heikka , J. and Waniganayke, M. (2011). Pedagogical leadership from a distributed perspective within the context of early childhood education. International Journal of Leadership in Education, 14 (4), 499-512.

Hopkins, D. (2001). School improvement for real (Educational and change development). London: Routledge.

Hoy, W. and DiPaola, M.(Eds.) (2010). Analyzing school contexts: Influences of principals and teachers in the service of students. Charlotte, NC: Information Age Publishing.

Jappinen, A. and Sarjia, A. (2011). Distributed pedagogical leadership and generative dialogue in educational nodes. Management in Education, 26 (2), 64-72.

Kagan, S. and Bowman, B. (Eds.) (1997). Leadership in early care and education. Washington, DC: NAEYC.

Kezar, A., Carducci, R. and Contreras-McGavin, M. (2006). Rethinking the "L" Word in higher education: The revolution of research on leadership. ASHE-ERIC Higher Education Report, 31(6).

Kough, T. and Tobin,B. (2001). Postmodern leadership and the policy lexicon from theory: Proxy to practice. Paper presented in the Pan-Canadian Education Research Agenda 
Symposium Teacher Education/Educator Training: Current Trends and Future Directions, May 22-23, Laval University, Quebec City.

Lefstein, A. (2005). Thinking about the technical and the personal in teaching. Cambridge Journal of Education, 35 (3), 333-356.

Lipman, M. (2003). Thinking in education. New York, NY: Cambridge.

MacNeill, N., Cavanagh, R. and Silcox, S. (2003). Pedagogic principal leadership. Management in Education, 17(4), 14-17.

Mahrdt, H. (2007). 'Phronesis bei Aristoteles und Hannah Arendt'. Deutsche Zeitschrift fuer Philosophie, 55(4), 587-603. [translated from the original]

Male, T. and Palaiologou, I. (2012). Learning-centred leadership or pedagogical leadership? An alternative approach to leadership in education contexts. International Journal of Leadership in Education, 15 (1), 107-118.

Male, T. and Palaiologou, I. (2015). Pedagogical leadership in the $21^{\text {st }}$ century: Evidence from the field. Educational Management, Administration and Leadership. 43 (2), 214-231.

Moore, A., George, R. and Halpin D. (2002). The developing role of the headteacher in English schools: Management, leadership and pragmatism. Educational Management Administration and Leadership, 30(2), 175-188.

Mortimore, P. (Ed.) (1999). Understanding pedagogy and its impact on learning. London: Paul Chapman.

Murphy, J (2010). The educator's handbook for understanding and closing achievement gaps. Thousand Oaks, CA: Corwin.

Ofsted (2002). The curriculum in successful primary schools. London: Ofsted Publications.

Ofsted (2004). Inspection report: [...] Secondary School. London: Ofsted Publications.

Ofsted (2009). Twelve outstanding secondary schools: Excelling against the odds. London: Ofsted Publications.

Petrie, P. (2005) Extending 'pedagogy'. Journal of Education for Teaching, 31, 293-296.

Selznick, P. (1983). Leadership in administration: A sociological interpretation. Berkeley, CA: University of California: Berkeley Press.

Sergiovanni, T. (1984). Leadership and excellence in schooling. Educational Leadership, 41(5), 4-13.

Sergiovanni, T. (1990). Adding value to leadership gets extraordinary results. Educational Leadership, 47 (8), 23-27. 
Sergiovanni, T (1992). Moral leadership: Getting to the heart of school improvement, San Francisco, CA: Jossey-Bass.

Sergiovanni, T. (1996). Leadership for the schoolhouse: How is it different? Why is it important? SanFrancisco: Jossey-Bass.

Sergiovanni, T. (1998). Leadership as pedagogy, capital development and school effectiveness. International Journal of Leadership in Education, 1: 37-46.

Siraj-Blatchford, I. (2009). 'Early childhood education'. In: T. Maynard and N. Thomas (Eds.). An introduction to early childhood studies (2/E). London: SAGE, 1-17.

Smith S, (2013). Speech to British Council, Tokyo. The Guardian, 22 January, 32.

Sorenson, G. (2002). An intellectual history of leadership studies: The role of James MacGregor Burns [Online]. The James MacGregor Burns Academy of Leadership. Available at: www.academy.umd.edu/publications/presidential_leadership/sorenson_apsa.html, Accessed 26 April, 2012.

Southworth, G. (2002). Instructional leadership in schools: Reflections and empirical evidence. School Leadership and Management, 22 (1) 73-91.

Sumsion, J., Barnes, S., Cheeseman S., Harrison, L. and Kennedy, A. (2009). Insider perspectives on developing belonging, being \& becoming: The early years learning framework for Australia. Australasian Journal of Early Childhood, 34 (4), 4-14.

Van Manen. M. (1991). The tact of teaching: The meaning of pedagogical thoughtfulness. Albany: State University of New York Press.

Vierce A. (1995). The cycles of global leadership. American Journal of Management Development, 1(3), 11-17.

Vygotsky, L.S. (1934/1986). Thinking and speech: Collected works. Volume 11, p. 347. Cambridge, MA: MIT Press.

Watkins , C. and Mortimore, P. (1999). 'Pedagogy: What do we know?' In: P.Mortimore. (Ed.) Understanding pedagogy and its impact on learning. London: Paul Chapman, 1-19.

Webster, R. (2009). Why educators should bring an end to pedagogy, Australian Journal of Teacher Education, 34, 42-53.

Yates, L. (2009). From curriculum to pedagogy and back again: Knowledge, the person and the changing world, Pedagogy, Culture and Society, 17, 17-28. 